\title{
Review of the epidemiology of overactive bladder
}

\author{
This article was published in the following Dove Press journal: \\ Research and Reports in Urology \\ 6 June 2016 \\ Number of times this article has been viewed
}

\section{Renu S Eapen \\ Sidney B Radomski \\ Division of Urology, Toronto Western Hospital, University of Toronto, University Health Network, Toronto, ON, Canada}

\begin{abstract}
Overactive bladder (OAB) is common in both men and women. It is a symptom complex that causes significant detriment to quality of life in patients. Although the prevalence of OAB is similar in both sexes, there are sex-specific differences in individual symptoms and the impact on quality of life. The coexistence of benign prostatic hyperplasia with OAB can worsen quality of life in men. This review examines the major studies that looked at the epidemiology of OAB as it relates to both sexes. It focuses on both the overall prevalence rates and the incidence of individual symptoms. This paper also addresses the level of bother and quality of life in men and women with OAB. In addition, the relationship between OAB and benign prostatic hyperplasia is reviewed.
\end{abstract}

Keywords: overactive bladder, prevalence, sex, LUTS, BPH, quality of life

\section{Introduction}

Overactive bladder $(\mathrm{OAB})$ is a prevalent condition in both men and women. It may have a significant impact on overall quality of life, sexual function, sleep, and mental health. According to the International Continence Society (ICS) definition, OAB consists of urinary urgency with or without urge incontinence, often accompanied by frequency and nocturia. The urodynamic characteristic of OAB is detrusor overactivity (DO). Numerous publications have studied the prevalence of OAB in developed countries and assessed the impact it has on quality of life with various results. ${ }^{1,2}$ Although the overall prevalence of OAB is similar between the two sexes, there are sex-specific differences in the prevalence of various symptoms within the OAB complex. ${ }^{3,4}$ Anatomical and physiological differences in the lower urinary tract of males and females may help to explain these variations. ${ }^{4}$ Additionally, the underlying mechanisms that cause the outwardly similar symptomatology in men and women may be different. This review focuses on the epidemiology of OAB. ${ }^{5-9}$

\section{EPIC study}

This is one of the largest population-based surveys that studied the prevalence of lower urinary tract symptoms (LUTS) and OAB. Conducted in five countries, including Canada, Germany, Italy, Sweden, and the UK, the EPIC study was a cross-sectional telephone survey of adults aged $>18$ years. ${ }^{6,7}$ A computer-assisted telephone interview system was used, followed by a questionnaire that looked at patient-specific categories such as demographics and comorbidities. The study had $>19,000$ participants and
Correspondence: Sidney B Radomski Division of Urology, Toronto Western Hospital, 399 Bathurst Street, Toronto, ON M5T 2S8, Canada

Email Sidney.Radomski@uhn.ca 
showed an overall OAB prevalence of $11.8 \%$, with similar rates in men and women. ${ }^{6}$

This study used ICS definitions of LUTS and OAB to survey the prevalence of various symptoms in the population. The EPIC study showed that the prevalence of LUTS suggestive of OAB was $10.8 \%$ in men and $12.8 \%$ in women. ${ }^{6}$ It can be seen from the EPIC study that the incidence of LUTS in general was similar but slightly more common in women than in men $(66.6 \%$ vs $62.5 \%) .{ }^{6}$ When divided into storage and voiding symptoms, sex differences are apparent. Storage symptoms were more common in women $(59.2 \%)$ than in men $(51.3 \%)$. On the other hand, voiding LUTS, such as intermittency, slow stream, and straining, were more common in men $(25.7 \%)$ than in women $(19.5 \%)$. The same was true for postmicturition symptoms such as postmicturition dribble or incomplete emptying, with prevalence being higher in men $(16.9 \%)$ than in women $(14.2 \%)$. Looking specifically at LUTS that define OAB, these were reported in $12.8 \%$ of women and $10.8 \%$ of men. This study opposes the commonly held misconception that OAB symptoms affect mostly older individuals. Approximately $73 \%$ of men and $72 \%$ of women who participated in the EPIC study were $<60$ years of age. Among the participants aged $40-59$ years, $51 \%$ of men and $56 \%$ of women experienced storage symptoms. Among those aged $<39$ years, $38 \%$ of men and $49 \%$ of women experienced storage symptoms. ${ }^{6}$ However, it appears that the prevalence of OAB symptoms does increase with age in both sexes.

Urinary incontinence (UI) has also been studied extensively, and the prevalence rates vary widely. The EPIC study reported that women had a much higher rate of any UI (urge, mixed, stress, and other) than men (13.1\% vs 5.4\%). ${ }^{6}$ Stress urinary incontinence was the most common type in women, and other urinary incontinence (urge, mixed) was more common in men.

The EPIC study assessed the prevalence of frequency in the study population, which largely depends on the definition used. ICS defined frequency as the perception of urinating too often during the daytime. ${ }^{7}$ Using this definition, the EPIC study reports that $31 \%$ of men and $25 \%$ of women with $\mathrm{OAB}$ symptoms had frequency. ${ }^{7}$ Of these, $75 \%$ of men and $60 \%$ of women urinated eight or fewer times during the day, most of them falling within the five to eight voids per day range. ${ }^{7}$ When a different definition of frequency is applied, that is, voiding frequencies of greater than eight times per day, the prevalence of frequency decreases to $12 \%$ of men and $19 \%$ of women with OAB. Women with OAB and ICS defined frequency had a higher daytime voiding frequency than men
( 8.2 vs 7 times per day). Women were more likely than men (19\% vs $12 \%$ ) to report frequency of more than eight times per day. Furthermore, women were more likely to be bothered by urinary frequency than men ( $66 \%$ vs $46 \%))^{7}$

The EPIC study used the ICS definition of nocturia as one or more voids per night. The EPIC study found that the general prevalence of nocturia was $48.6 \%$ in men and $54.5 \%$ in women. However, in those with OAB, the prevalence was $75 \%$ of men and $74 \%$ of women indicating that nocturia occurs commonly in this syndrome. If nocturia is defined as two or more voids per night, the prevalence decreases significantly in both sexes (20.9\% of men and $24 \%$ of women).

The EPIC study confirmed that most patients with OAB had a combination of symptoms. Urgency with or without UI in the absence of frequency or nocturia was present in only $21 \%$ of men and $23 \%$ of women. Approximately $50 \%$ of OAB patients had a combination of two symptoms, and approximately one-third of patients reported a combination of three OAB symptoms. ${ }^{7}$ It was also rare to have patients who had all four symptoms ( $5 \%$ of men and $7 \%$ of women). Also rare was the incidence of frequency in the absence of nocturia, occurring in only $4 \%$ of both sexes with OAB (Table 1$){ }^{7}$

\section{NOBLE study}

The National Overactive Bladder Evaluation (NOBLE) program was developed to estimate the prevalence of OAB and its burden in the United States. ${ }^{8}$ It also assessed the influence of sex on OAB and its symptoms. Furthermore, it focused on the impact of $\mathrm{OAB}$ on quality of life, sleep, and general mental health. It was conducted as a computer-assisted telephone interview followed by a self-administered questionnaire to assess quality of life. Out of $>17,000$ households that were contacted, 5,204 participants completed the interview. ${ }^{8}$ The study showed an overall OAB prevalence of $\sim 16 \%$ with no significant differences between the two sexes $(16 \%$ in men, $16.9 \%$ in women). The NOBLE study did not confirm the general belief that $\mathrm{OAB}$ and urgency symptoms are more common in women than men.

The NOBLE study revealed that specific OAB symptoms were more common in women than in men but with increasing age, especially over the age of 60 years, symptoms were predominant in men. Although the overall prevalence of $\mathrm{OAB}$ in men and women was similar, the incidence of $\mathrm{OAB}$ with and without urge incontinence showed significant sex variation. The NOBLE study demonstrated that in all age groups, OAB without UI was more common in men than in women. Urge incontinence increased with age in both 
Table I Summary of key studies

\begin{tabular}{|c|c|c|c|c|}
\hline & $E_{P I C}^{6,7}$ & NOBLE $^{8}$ & EpiLUTS 5 & Milsom ${ }^{9}$ \\
\hline Geography & $\begin{array}{l}\text { Canada, Germany, Italy, } \\
\text { Sweden, UK }\end{array}$ & USA & USA & $\begin{array}{l}\text { France, Germany, Italy, Spain, } \\
\text { Sweden, UK }\end{array}$ \\
\hline Participants & 19,165 & 5,204 & 20,000 & 16,776 \\
\hline Age of participants & $\geq 18$ years & $\geq 18$ years & $\geq 40$ years & $\geq 40$ years \\
\hline Survey technique & Telephone & Telephone & Internet & Telephone/direct \\
\hline $\begin{array}{l}\text { Overall OAB } \\
\text { prevalence (\%) }\end{array}$ & 11.8 & 16.5 & 35.6 & 16.6 \\
\hline Female & 12.8 & 16.9 & 43.1 & 17.4 \\
\hline Male & 10.8 & 16.0 & 27.2 & 15.6 \\
\hline Any LUTS (\%) & - & - & - & - \\
\hline Female & 66.6 & - & - & - \\
\hline Male & 62.5 & - & - & - \\
\hline Urinary incontinence (\%) & - & - & - & - \\
\hline Female & 13.1 & - & - & - \\
\hline Male & 5.4 & - & - & - \\
\hline Other & $\begin{array}{l}\text { Frequency: female } 25 \% \text {, } \\
\text { male } 31 \% \text {; nocturia: female } \\
54.5 \% \text {, male } 48.6 \%\end{array}$ & $\begin{array}{l}\text { Prevalence of OAB with/ } \\
\text { without urge incontinence } \\
\text { similar in women ( } 9.3 \% \text { vs } \\
7.6 \%) \text {; prevalence of OAB with/ } \\
\text { without urge incontinence } \\
\text { different in men ( } 2.6 \% \text { vs } 13.4 \% \text { ) }\end{array}$ & $\begin{array}{l}\text { Urgency and urge urinary } \\
\text { incontinence: female } 15.3 \% \text {, } \\
\text { male } 9.3 \%\end{array}$ & $\begin{array}{l}\text { Frequency: } 85 \% \text {; urgency } \\
54 \% \text { (no difference between } \\
\text { women and men); urge } \\
\text { urinary incontinence: } 36 \% \\
\text { (more prevalent in women) }\end{array}$ \\
\hline
\end{tabular}

Abbreviations: NOBLE, National Overactive Bladder Evaluation; EpiLUTS, epidemiology of lower urinary tract symptoms; OAB, overactive bladder.

sexes, increasing from $2 \%$ to $19 \%$ in women after the age of 44 years and from $0.3 \%$ to $9 \%$ in men with a marked increase after 64 years. ${ }^{8}$ The age-related increase in $\mathrm{OAB}$ with UI is much stronger in women than in men $(P<0.0001)$. While there is a steady increase with age of OAB with UI in women throughout their lifetime, the main increase in the prevalence of OAB with UI in men only occurs after the age of 65 years. On the other hand, the prevalence of $\mathrm{OAB}$ without UI has a steeper age-related increase in men than in women $(P<0.0001)$. This almost tripled in men from $8.5 \%$ in those $<45$ years of age to $21.8 \%$ in men after 55 years. In women, $\mathrm{OAB}$ without UI increased far more gradually and reached a plateau after the age of 44 years. Furthermore, while the prevalence of $\mathrm{OAB}$ with and without $\mathrm{UI}$ in women was similar (9.3\% and 7.6\%), in men the prevalence of $\mathrm{OAB}$ with UI $(2.6 \%)$ was much lower than the prevalence of $\mathrm{OAB}$ without UI $(13.4 \%){ }^{8}$

The NOBLE study also discovered an association between OAB with UI and body mass index (BMI) in women but not in men. Women with $\mathrm{BMI}>30$ were 2.2 times more likely to have $\mathrm{OAB}$ with UI than women with $\mathrm{BMI}<24 .{ }^{8}$ Men who reported a history of prostate problems had a higher prevalence ratio of $\mathrm{OAB}$ with and without UI. Given that the overall prevalence of $\mathrm{OAB}$ is similar in men and women, the sex differences seen in UI suggest that there is a sex-specific cause for UI that could be attributed to the anatomical and physiological differences in urinary continence mechanisms such as a shorter female urethra and the effect of pregnancy and vaginal delivery on the pelvic floor. ${ }^{8}$

\section{EpiLUTS study}

The epidemiology of lower urinary tract symptoms (EpiLUTS) survey was a population-based, cross-sectional survey conducted in the US, UK, and Sweden to evaluate the prevalence and bother of $\mathrm{OAB}$ and to update the results of the NOBLE survey done in 2003. Specific to the United States, 20,000 men and women aged $>40$ years were randomly selected from 1.5 million internet panel members. ${ }^{5}$ EpiLUTS examined the frequency of OAB symptoms segregated into categories and studied the level of bother in each category. The prevalence of $\mathrm{OAB}$ depended on how $\mathrm{OAB}$ was defined. When symptoms were defined as "sometimes", the overall prevalence was $35.6 \%$. When defined as "often", the overall prevalence decreased to $24.7 \% .{ }^{5}$ No matter how it was defined, the prevalence increased with increasing age.

Sex-specific differences were evident in the EpiLUTS study. In men, the prevalence rates of OAB symptoms "sometimes" and "often" were $27.2 \%$ and $15.8 \%$, respectively, whereas in women, the prevalence rates of OAB symptoms "sometimes" and "often" were $43.1 \%$ and $32.6 \%$, respectively. ${ }^{5}$ Women had an overall higher prevalence of symptoms such as urgency, UI, or both. All these symptoms increased in prevalence with increasing age in both sexes. 
The EpiLUTS study examined symptom complexes in OAB. Isolated symptoms were rare in OAB. Urgency in isolation was present in $15.6 \%$ of men and $10.9 \%$ of women. Looking at urgency and urge incontinence as the only two OAB symptoms, this complex was reported in $9.3 \%$ of men and $15.3 \%$ of women. ${ }^{5}$ All four symptoms of OAB, including urgency, urge incontinence, frequency, and nocturia, were found in $16 \%$ of men and $20 \%$ of women.

\section{Milsom study}

Milsom et al ${ }^{9}$ conducted a population-based prevalence study to determine the prevalence and symptoms of OAB. The surveys were carried out in France, Germany, Italy, Spain, Sweden, and the UK. Telephone and direct interviews were conducted in 16,776 randomly selected men and women aged $>40$ years. ${ }^{9}$ The researchers used specific definitions of symptoms of OAB and stress incontinence and prostatic obstruction. The Milsom study found an overall prevalence of OAB symptoms of $16.6 \%{ }^{9}$ This study also examined the rate at which $\mathrm{OAB}$ patients sought medical advice and treatment.

Women were slightly more likely than men to report $\mathrm{OAB}$ symptoms with the sex-specific prevalence being $15.6 \%$ in men and $17.4 \%$ in women, even though other studies have suggested that male $\mathrm{OAB}$ was much more likely to have underlying DO than female OAB. ${ }^{10}$ The Milsom study looked at individual symptoms that occur in this condition, specifically frequency (85\%), urgency (54\%), and urge incontinence (36\%), in order of most to least common. ${ }^{9}$ The overall prevalence of frequency and urgency was comparable irrespective of sex. However, urge incontinence was found to be more prevalent among women than men. ${ }^{9}$ It was found to be less common in both sexes to present with an isolated symptom (eg, frequency alone) or to present with all the symptoms of OAB. Most people presented with a varying mix of symptoms. The presence of all these symptoms increases with increasing age.

The prevalence of OAB symptoms in men increases slowly until the age of 70 years, but then a sharp increase can be observed after 75 years of age, with a slight fall in prevalence between the ages of 70 years and 75 years. In women, there is also a gradual increase seen until the age of 60 years, with a leveling off seen between 60 years and 70 years of age and a gradual increase in prevalence thereafter. ${ }^{9}$

\section{Quality of life}

Studies assessing quality of life highlight the significant negative impact that $\mathrm{OAB}$ has on daily activities, mental health, and sexual function..$^{5-7,9,11,12}$ The Milsom study examined the behaviors of individuals with OAB symptoms. ${ }^{9}$ Sixtyfive percent of participants reported that $\mathrm{OAB}$ symptoms adversely affected their quality of life. Medical consultation rate was reasonably high in this study at $61 \%$. However, less than one-third of patients who sought medical help were receiving medications. Furthermore, frequency and urgency symptoms were almost as much of a reason to seek help as was UI. Two-thirds of participants with OAB had tried a number of conservative measures such as decreasing fluid intake to manage their symptoms. The EpiLUTS study indicated that OAB symptoms are more bothersome for women than men. ${ }^{5}$ This differs from the EPIC study where almost identical levels of bother were reported by women (53\%) and men (54\%) who suffered OAB. ${ }^{67}$ Women were twice as likely as men to use various coping strategies such as physiotherapy and absorbent products as nonmedical management of OAB. ${ }^{9}$ The EpiLUTS study suggests that the motivation to seek medical help is related to the number of symptoms, the level of bother, and the age of the patient. ${ }^{5}$ It appears that older patients are more likely to consult a doctor than younger patients with OAB. One of the main reasons for not seeking help or advice was the lack of awareness that effective treatment was available for such conditions.

The review of Irwin et al of the EPIC study showed that the degree of bother among OAB sufferers increased as the number of LUTS increased. ${ }^{7}$ Twelve different LUTS were assessed by the EPIC study. In those suffering only urgency, $14 \%$ of men and $8 \%$ of women were bothered by their symptoms. In those who reported urgency and one other LUTS, $28 \%$ of men and $33 \%$ of women experienced reportable bother. The prevalence of bother increased significantly in those who reported urgency with two other LUTS. This indicates that urgency alone is not as bothersome to most OAB patients, and it is the addition of further LUTS that dramatically impacts on the level of bother and quality of life. The EpiLUTS study confirmed the findings of the EPIC study that the likelihood of bother increased with the number of OAB symptoms present with $100 \%$ of men and $90 \%$ of women with all four OAB symptoms reporting that they were bothered at least "somewhat".

The effect of nocturia on quality of life is significant. It is controversial if one episode of nocturia per night is significant, since many experts believe this falls within the normal clinical spectrum. ${ }^{7}$ However, in the EPIC study, among OAB sufferers, $19 \%$ of men and $24 \%$ of women with one episode of nocturia per night were bothered by it. The prevalence increases dramatically when sufferers experience two or 
Table 2 Bother level in key studies

\begin{tabular}{|c|c|c|}
\hline $\mathrm{EPIC}^{6,7}$ & $\begin{array}{l}\text { OAB symptoms have } \\
\text { similar bother in women } \\
(53 \%) \text { and men }(54 \%)\end{array}$ & $\begin{array}{l}\text { The degree of bother increased } \\
\text { as the number of LUTS increased }\end{array}$ \\
\hline NOBLE $^{8}$ & No data & No data \\
\hline EpiLUTS $^{5}$ & $\begin{array}{l}\text { OAB symptoms more } \\
\text { bothersome in women } \\
(67.6 \%) \text { than in men } \\
(60 \%)\end{array}$ & $\begin{array}{l}\text { Motivation to seek medical help } \\
\text { was related to the number of } \\
\text { symptoms, level of bother, and age } \\
\text { of patient }\end{array}$ \\
\hline Milsom 9 & $\begin{array}{l}\text { Quality of life affected } \\
\text { in } 65 \% \text { of patients with } \\
\text { OAB: women } 67 \% \text {, } \\
\text { men } 65 \%\end{array}$ & $\begin{array}{l}\text { Less than one-third of patients } \\
\text { who sought medical help were } \\
\text { currently receiving medications }\end{array}$ \\
\hline
\end{tabular}

Abbreviations: NOBLE, National Overactive Bladder Evaluation; EpiLUTS, epidemiology of lower urinary tract symptoms; OAB, overactive bladder.

more episodes of nocturia. Studies have shown that even in healthy individuals, any episodes of nocturia can have a significantly negative impact on quality of life, sleep, work performance, and general well-being. ${ }^{7}$ This impact is greater in those who suffer from multisymptom OAB (Table 2).

\section{Coexistence of OAB with benign prostatic hyperplasia}

There is presumed to be an association between $\mathrm{OAB}$ and bladder outlet obstruction (BOO) secondary to benign prostatic hyperplasia (BPH) with several studies recognizing them as common comorbid conditions. ${ }^{13} \mathrm{Up}$ to $50 \%$ of men with $\mathrm{BOO}$ are estimated to have OAB symptoms. ${ }^{14,15}$ Some studies have noted that $50 \%$ of men with LUTS and urodynamically confirmed BOO have DO. ${ }^{16}$ OAB symptoms may develop secondary to BOO. ${ }^{17}$ In these men, treatment can be challenging as there is theoretical concern that anticholinergic treatment may precipitate urinary retention. On the other hand, studies have estimated that $40 \%$ of men with $\mathrm{BOO}$ and $\mathrm{OAB}$ continue to have overactivity symptoms despite treatment and relief of BOO. ${ }^{14,17}$ Abrams et al ${ }^{18}$ proposed some of the mechanisms by which BOO leads to DO, which include denervation from ischemia, physiological changes in the bladder wall, and neural control of bladder contraction induced by BOO. Early explanations include "increased irritability" of the bladder associated with BOO. ${ }^{19}$ The prevalence of $\mathrm{BOO}$ increases with age. Therefore, it is more likely for older men with symptomatic $\mathrm{OAB}$ to have underlying $\mathrm{BOO}$ as a potential cause for their symptoms. Men younger than 50 years of age with OAB symptoms are less likely to have significant BOO. ${ }^{15}$ De Nunzio et al studied the evolution of bladder overactivity in men with BOO. They examined 255 patients with symptomatic $\mathrm{BOO}$ who were stratified according to the treatment they received including medical therapy, surgical therapy, and watchful waiting. ${ }^{19}$ They underwent urodynamic testing both at baseline and at a mean of 2 years of follow-up. In general, DO was highly prevalent in patients with BOO. Overall, $52 \%$ and $40 \%$ of patients with BOO demonstrated DO at baseline and follow-up, respectively. When stratified according to the treatments received, these figures were $45 \%$ and $55 \%$ in the watchful waiting group, $35 \%$ and $30 \%$ in the alfuzosin group, $46 \%$ and $30 \%$ in the transurethral incision group, and $68 \%$ and $31 \%$ in the prostatectomy group. ${ }^{19}$ This suggests that various treatments for $\mathrm{BOO}$ can have an impact on $\mathrm{DO}$ over time with decreased incidence of DO in these patients. Lee et $\mathrm{al}^{14}$ studied 144 patients with LUTS in a prospective analysis. Urodynamic studies were performed to look for DO. Of these, $47 \%$ of patients had BOO and OAB. Only $35 \%$ of patients with coexisting $\mathrm{BOO}$ and $\mathrm{OAB}$ reported symptomatic improvement after taking doxazosin monotherapy for 3 months. Of the remaining $65 \%$ who did not respond, $73 \%$ had a symptomatic improvement after the addition of tolterodine. ${ }^{14}$ Of the 16 patients with $\mathrm{BOO}$ only, who did not respond to doxazosin monotherapy, six patients reported symptomatic improvement after the addition of tolterodine. The current literature supports the use of combination therapy with anticholinergic agents and alpha blockers. ${ }^{17}$ Studies evaluating anticholinergic and beta 3 agonist (mirabegron) therapies have shown that both can be safely administered in men with $\mathrm{BOO}$ and $\mathrm{OAB}$ without negative effects on voiding or urodynamic pressures. ${ }^{13}$ It has also been demonstrated that fesoterodine in flexible doses $(4 \mathrm{mg}$ or $8 \mathrm{mg}$ ) in men with persistent OAB symptoms is well tolerated. ${ }^{15}$

\section{Neurogenic versus nonneurogenic OAB}

In this review, we did not differentiate between neurogenic and nonneurogenic $\mathrm{OAB}$. The studies that we examined in this review did not specifically include or exclude neurogenic bladder, and we believe this review represents $\mathrm{OAB}$ in the general population. In general, the studies excluded participants who were pregnant or had active urinary tract infections. ${ }^{5,8,9}$ The NOBLE and Milsom studies specified the definition of OAB as being urinary urgency with or without urge incontinence, in the absence of pathologic or metabolic factors that would otherwise explain the symptoms. ${ }^{8,9}$ The NOBLE study sought information regarding medical conditions such as diabetes, heart failure, multiple sclerosis, Parkinson's disease, spinal cord injury, cancer, and interstitial cystitis. ${ }^{8}$ This review excluded secondary causes of $\mathrm{OAB}$ symptoms including diabetes, heart failure, cancer, bladder surgery, previously diagnosed prostate enlargement, interstitial cystitis, pregnancy, recent birth, medications, and excessive fluid intake. This made 
$47 \%$ of participants who completed the survey ineligible. ${ }^{8}$ The Milsom study included patients with or without a possible neurological cause for their symptoms. ${ }^{9}$ Their exclusion criteria included urinary tract infections, pure stress incontinence, and symptoms suggestive of prostatic obstruction.

\section{Summary}

Multiple studies have assessed the prevalence of OAB and the impact it has on quality of life. We have presented here the significant findings of a number of studies conducted in this area. The information presented in these studies is often contradictory and confusing. However, there were some common threads. $\mathrm{OAB}$ is common in both women and men. The prevalence of $\mathrm{OAB}$ and its symptoms increases with increasing age in both sexes. While the overall prevalence is similar in both sexes, there are some sex-specific differences. Urge incontinence is more common in women than in men. Isolated symptoms are rare in $\mathrm{OAB}$. It is much more common to have a combination of symptoms in both sexes with frequency being the most commonly reported symptom. OAB in both sexes has a significant impact on the quality of life, quality of sleep, and mental health. Furthermore, the level of bother increases with the number of symptoms experienced. BPH and BOO commonly coexist with $\mathrm{OAB}$ and worsen the level of bother and quality of life in men. Assessment of LUTS in men should take this into account, and treatment should be tailored to address both.

\section{Disclosure}

Doctor Renu S Eapen has no disclosures. Doctor Sidney B Radomski is on the advisory board of Allergan, Merus Labs, Astellas, Lilly, and Pfizer. He is also involved in clinical trials with Allergan and Astellas. The authors report no other conflicts of interest in this work.

\section{References}

1. Herschorn S, Kaplan SA, Sun F, Ntanios F. Do patient characteristics predict responsiveness to treatment of overactive bladder with antimuscarinic agents? Urology. 2014;83(5):1023-1029.

2. Valentini FA, Marti BG, Robain G. Idiopathic and neurogenic detrusor overactivity: do the different patterns have urodynamic characteristics related to gender or neurological condition? Int Braz J Urol. 2013;39(5):663-670.
3. Link CL, Steers WD, Kusek JW, McKinlay JB. The association of adiposity and overactive bladder appears to differ by gender: results from the Boston Area Community Health survey. J Urol. 2011;185(3):955-963.

4. Patra PB, Patra S. Sex differences in the physiology and pharmacology of the lower urinary tract. Curr Urol. 2013;6(4):179-188.

5. Coyne KS, Sexton CC, Vats V, Thompson C, Kopp ZS, Milsom I. National community prevalence of overactive bladder in the United States stratified by sex and age. Urology. 2011;77(5):1081-1087.

6. Irwin DE, Milsom I, Hunskaar S, et al. Population-based survey of urinary incontinence, overactive bladder and other lower urinary tract symptoms in five countries: results of the EPIC study. Eur Urol. 2006;50(6):1306-1315.

7. Irwin DE, Abrams P, Milsom I, Kopp Z, Reilly K; EPIC Study Group. Understanding the elements of overactive bladder: questions raised by the EPIC study. BJU Int. 2008;101(11):1381-1387.

8. Stewart WF, Van Rooyen JB, Cundiff GW, et al. Prevalence and burden of overactive bladder in the United States. World J Urol. 2003;20(6):327-336.

9. Milsom I, Abrams P, Cardozo L, Roberts RG, Thüroff J, Wein AJ. How widespread are the symptoms of an overactive bladder and how are they managed? A population based prevalence study. BJU Int. 2001;87(9):760-766.

10. Sekido N, Hinotsu S, Kawai K, Shimazui T, Akaza H. How many uncomplicated male and female overactive bladder patients reveal detrusor overactivity during urodynamic study? Int J Urol. 2006;13(10):1276-1279.

11. Teloken C, Caraver F, Weber FA, et al. Overactive bladder: prevalence and implications in Brazil. Eur Urol. 2006;49(6):1087-1092.

12. Temml C, Heidler S, Ponholzer A, Madersbacher S. Prevalence of the overactive bladder syndrome by applying the International Continence Society definition. Eur Urol. 2005;48(4):622-627.

13. Nitti VW, Rosenberg S, Mitcheson DH, He W, Fakhoury A, Martin NE. Urodynamics and safety of the $\beta_{3}$-adrenoceptor agonist mirabegron in males with lower urinary tract symptoms and bladder outlet obstruction. J Urol. 2013;190(4):1320-1327.

14. Lee JY, Kim HW, Lee SJ, Koh JS, Suh HJ, Chancellor MB. Comparison of doxazosin with or without tolterodine in men with symptomatic bladder outlet obstruction and an overactive bladder. BJU Int. 2004;94(6):817-820.

15. Kaplan SA, Roehrborn CG, Gong J, Sun F, Guan Z. Add-on fesoterodine for residual storage symptoms suggestive of overactive bladder in men receiving $\alpha$-blocker treatment for lower urinary tract symptoms. $B J U$ Int. 2012;109(12):1831-1840.

16. Vuichoud C, Loughlin K. Benign prostatic hyperplasia: epidemiology, economics and evaluation. Can J Urol. 2015;22(suppl 1):1-6.

17. Chapple CR, Herschorn S, Abrams P, Wang JT, Brodsky M, Guan Z. Efficacy and safety of tolterodine extended-release in men with overactive bladder symptoms treated with an $\alpha$-blocker: effect of baseline prostate-specific antigen concentration. BJU Int. 2010;106(9): 1332-1338.

18. Abrams P, Kaplan S, De KoningGans HJ, Millard R. Safety and tolerability of tolterodine for the treatment of overactive bladder in men with bladder outlet obstruction. J Urol. 2006;175(3 Pt 1):999-1004. discussion 1004.

19. de Nunzio C, Franco G, Rocchegiani A, Iori F, Leonardo C, Laurenti C. The evolution of detrusor overactivity after watchful waiting, medical therapy and surgery in patients with bladder outlet obstruction. J Urol. 2003;169(2):535-539.
Research and Reports in Urology

Publish your work in this journal

Research and Reports in Urology is an international, peer-reviewed, open access journal publishing original research, reports, editorials, reviews and commentaries on all aspects of adult and pediatric urology in the clinic and laboratory including the following topics: Pathology, pathophysiology of urological disease; Investigation and treatment of

\section{Dovepress}

urological disease; Pharmacology of drugs used for the treatment of urological disease. The manuscript management system is completely online and includes a very quick and fair peer-review system, which is all easy to use. Visit http://www.dovepress.com/testimonials.php to read real quotes from published authors. 